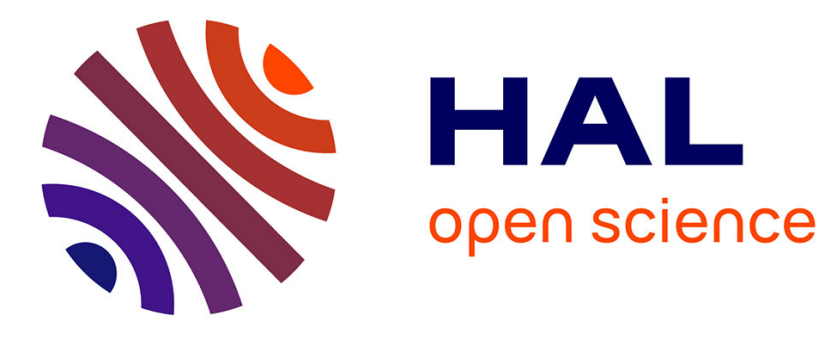

\title{
French neuropsychological procedure consensus in epilepsy surgery
}

Hélène Brissart, Mélanie Planton, Mathias Bilger, Christine Bulteau, Natacha

Forthoffer, Victoria Guinet, Sophie Hennion, Catherine Kleitz, Virginie

Laguitton, Hélène Mirabel, et al.

\section{To cite this version:}

Hélène Brissart, Mélanie Planton, Mathias Bilger, Christine Bulteau, Natacha Forthoffer, et al.. French neuropsychological procedure consensus in epilepsy surgery. Epilepsy \& Behavior, 2019, 100, pp.106522. 10.1016/j.yebeh.2019.106522 . hal-02395371

\section{HAL Id: hal-02395371 \\ https://hal.science/hal-02395371}

Submitted on 12 Aug 2021

HAL is a multi-disciplinary open access archive for the deposit and dissemination of scientific research documents, whether they are published or not. The documents may come from teaching and research institutions in France or abroad, or from public or private research centers.
L'archive ouverte pluridisciplinaire HAL, est destinée au dépôt et à la diffusion de documents scientifiques de niveau recherche, publiés ou non, émanant des établissements d'enseignement et de recherche français ou étrangers, des laboratoires publics ou privés.

\section{(c)(1)}

Distributed under a Creative Commons Attribution| 4.0 International License 


\title{
French neuropsychological procedure consensus in epilepsy surgery
}

\author{
H. Brissart ${ }^{\mathrm{a}, \mathrm{b}, *}$, M. Planton ${ }^{\mathrm{c}, \mathrm{d}}$, M. Bilger ${ }^{\mathrm{e}}$, C. Bulteau ${ }^{\mathrm{f}, \mathrm{g}}$, N. Forthoffer $^{\mathrm{a}}$, V. Guinet ${ }^{\mathrm{h}}$, S. Hennion ${ }^{\mathrm{i}}$, C. Kleitz ${ }^{\mathrm{e}}$, \\ V. Laguitton ${ }^{j}$, H. Mirabel $^{\mathrm{c}}$, C. Mosca ${ }^{\mathrm{k}}$, N. Pécheux ${ }^{\mathrm{l}}$, S. Pradier ${ }^{\mathrm{m}}$, S. Samson ${ }^{\mathrm{n}, \mathrm{o}}$, E. Tramoni $^{\mathrm{p}}$, V. Voltzenlogel ${ }^{\mathrm{q}}$, \\ M. Denos ${ }^{\mathrm{n}}$, M. Boutin ${ }^{\mathrm{r}}$
}

a Université de Lorraine, CNRS, CRAN, F-54000 Nancy, France

b Université de Lorraine, CHRU-Nancy, Service de Neurologie, F-54000 Nancy, France

c Neurology Department, Hôpital Pierre-Paul Riquet, CHU de Toulouse, Toulouse, France

d Toulouse NeuroImaging Center, Université de Toulouse, Inserm, UPS, France

e Neurology Department, Hôpital Hautepierre, CHRU Strasbourg, Strasbourg, France

${ }^{\mathrm{f}}$ Pediatric Neurosurgery Department, Rothschild Foundation Hospital, Paris, France

${ }^{g}$ Memory, Brain and Cognition (MC2Lab, EA 7536), Institute of Psychology Sorbonne Paris Cité University, Boulogne Billancourt, France

h Department of Functional Neurology and Epileptology, Hospices Civils de Lyon, Lyon, France

${ }^{i}$ Reference Center Rare Epilepsies, Epilepsy Unit, Univ. Lille, INSERM, CHU Lille, U1171 Degenerative and vascular cognitive disorders, Lille, France

j CINAPSE, Hôpital Henri Gastaut Centre Saint Paul, 13009 Marseille, France

${ }^{\mathrm{k}}$ Epilepsy Unit, $\mathrm{CHU}$, Grenoble-Alpes, France

${ }^{1}$ Epilepsy Unit, $\mathrm{CHU}$ Lille, France

${ }^{m}$ Functional Explorations of the Nervous System, Clinical Neurosciences Center, University Hospital Center Pellegrin, Bordeaux, France

${ }^{\mathrm{n}}$ Neurology Department, APHP, Paris, France

${ }^{\circ}$ Equipe Neuropsychologie: Audition, Cognition et Action (EA 4072), UFR de psychologie, Université Lille-Nord de France, Villeneuve d'Ascq, France

p INSERM U 751, Marseille, France; Aix-Marseille Université, Faculté de Médecine, Marseille, France

${ }^{q}$ Centre d'Etudes et de Recherches en Psychopathologie et Psychologie de la Santé, Université de Toulouse, UT2J, Toulouse, France

${ }^{\mathrm{r}}$ GHU-Paris Pôle Neuro-Sainte-Anne - Neurosurgery Unity 1, rue Cabanis, PARIS, France

Introduction: Neuropsychological assessment is an integral component of the surgical procedure in patients with epilepsy. As no French consensus for neuropsychological assessment was available, the main goal of this work was to define French neuropsychological procedure consensus in regard to literature review.

Method: A panel of expert in neuropsychology was created within the framework of the French League Against Epilepsy. A systematic search of publications from 1950 to 2017 listed in PubMed database was conducted leading to a classification of articles according to their level of scientific evidence. French neuropsychological procedure consensus was then carried out with an expert panel of expert.

Results: Low scientific evidence of neuropsychological data was reported. A panel of expert proposed a comprehensive neuropsychological assessment procedure including the exploration of intellectual efficiency, long-term memory, short-term and working memory, attention, executive functions, processing speed and motor skills, language, visual processing, praxis, psychobehavioral, and social cognition.

Discussion: A common procedure for assessing cognitive and psychobehavioral function is now available in patients with epilepsy undergoing surgical evaluation have been established, they may help to improve the quality of care and the patient experience. This work highlights the need of furthers investigations and the necessity to develop specific tools with normative data.

Abbreviations: AEDs, antiepileptic drug; EEG, electroencephalogram; FLAE, French League Against Epilepsy; FSIQ full-scale intelligence quotient; GAI, general ability index; ILAE, International League Against Epilepsy; MRI, magnetic resonance imaging; NAP, neuropsychological assessment procedure; PRI, perceptual reasoning index; PSI, processing speed index; TLE, temporal lobe epilepsy; VCI, verbal comprehension index; WMI, working memory index.

* Corresponding author at: Hôpital Central - Neurology Department, 29 avenue Maréchal de Lattre de Tassigny, 54035 NANCY Cedex, France.

E-mail address: h.brissart@chru-nancy.fr (H. Brissart).

\section{Introduction}

Epilepsy is one of the most common chronic neurological disorders. According to International League Against Epilepsy's (ILAE) definition, "epilepsy is a disorder of the brain characterized by an enduring predisposition to generate epileptic seizures and by the neurobiological, cognitive, psychological, and social consequences of this condition" [1]. Cognitive disorders are frequent at the onset of the disease (up to 70\%) [2] and are a major supplementary factor in occupational, social, 
and family disability in addition to those caused by seizures. Epilepsy surgery may represent a very successful treatment option for many patients not responding to pharmacological treatment [3]. The main goal is to stop seizures; however, it is not without cognitive risk [4].

The role of neuropsychological assessment is crucial in presurgical patients diagnosed with drug-resistant epilepsy. In this context, neuropsychological assessment procedure (NAP) aims to identify epilepsyrelated cognitive impairment and their etiologic attribution to lesions, drug treatment, and mood. The results of NAP contribute to each individual patient's postsurgical deficits risk prediction [5]. Major predictors of neuropsychological outcome include presurgical tests performances, which reflect functional integrity of the resected tissues and cognitive reserve capacities [5,6].

A special report from ILAE Neuropsychology Task Force [7] summarizes the role of the neuropsychological assessment and its framework. An inventory of current standard neuropsychological assessment in Europe has been published [8] showing high variability with 186 different tasks used. Authors argue that neuropsychological tests are not selected according to strong scientific evidence (fidelity, sensitivity, parallel form, etc.), but rather based on institutional constraints or personal choices. Currently, no international consensus for NAP has been published in epilepsy surgery. Furthermore, NAP is very dependent on native language and cultural background, which need to be taken into consideration within each country.

The main goal of this work is to define French neuropsychological procedure consensus in regard to neuropsychological systematic literature review.

\section{Methods}

In 2016, with the support of the French chapter of the ILAE, all centers dispensing epilepsy surgery in France were consulted about their neuropsychological practice. An online interview was sent to all neuropsychologists including ten questions about the organization of the surgery unit, the duration of systematic neuropsychological assessment and the tests used to assess cognitive functioning [see Appendix A for details]. Fifteen out of the 16 centers responded. Analysis of these results reported a high variability in neuropsychological assessment duration ranging from 1.5 to $6.5 \mathrm{~h}$. Regarding cognitive dimensions, the only consensus found concerned global efficiency with Wechsler intelligence scales [9], highlighting the heterogeneity and disparity in neuropsychological practices, as reported in the European survey [8].

Thereafter, a task force of experts in neuropsychology was created within the French Chapter of the ILAE. Every neuropsychologist meets at least 25 patients per year for more than two years as defined by Rosenow et al.[10]. A systematic literature review from 1950 to 2017 listed in PubMed database was conducted by a panel of experts using a combination of MeSH search terms. Keywords used were related to epilepsy and cognition (see Appendix B for details). For all citations, raters conducted an abstract review and excluded studies according the following criteria: 1 ) absence of cognitive data, 2) sample size inferior to 20 patients, 3) nonsurgical population, 4) patients with others etiologies, 5) patients with palliative treatment, 6) studies dealing with stimulations (EEG [electroencephalogram], Stereo electroencephalogram (SEEG), cognitive rehabilitation), and 7) animal's studies. All remaining citations then underwent a full text review using a clinical, neuropsychological, and methodological reading grid designed for this work. In details, for each study, demographic, clinical, and neuropsychological data, information on study design, and setting were extracted (see Appendix C). In addition, data characterizing neuropsychological assessment utilized in each study were categorized into cognitive groups based on the domains they are known or assumed to measure (IQ; speed processing; executive functions; memory; language; visual processing/spatial/constructive abilities; social cognition; and psychobehavioral data). Finally, each article was assigned a 4 point class scale depending on the strength of its methodological quality adapting the criteria used by the French Health Department (Haute Autorité de Santé). Class 1 included high statistical power randomized controlled trials and decision analysis based on well-conducted studies. Class 2 included low statistical power randomized controlled trials, well-conducted nonrandomized controlled studies and cohort studies. Class 3 included case-control studies. Class 4 included comparative studies with significant biases, retrospective studies, and case series. According to this classification, Class 1 corresponds to established scientific evidence, Class 2 corresponds to scientific presumption, and Classes 3 and 4 correspond to a low level of evidence.

\section{Results}

\subsection{Analysis of the literature review}

Of the 1920 originally identified abstracts extracted from PubMed database, 613 met the initial inclusion criteria. Further selection based on full text resulted in a final selection of 332 articles (see Fig. 1). Systematic literature review demonstrated a low evidence for neuropsychological purposes in these scientific reports with $0.9 \%$ of Class 1 studies, $8.1 \%$ of Class 2 studies and more than $90 \%$ of Classes 3 and 4 studies. Classes 3 and 4 studies were justified by retrospective design, missing data, absence of longitudinal design, absence of control group, and low statistical properties. No French studies are reported in Classes 1 and 2 . Only 11 (3,3\%) studies are reported with French language (nine conducted in France, one in Swiss, one in Canada).

Thus, as literature review reports very small number studies with high statistical power, and only 11 French studies are reported with low statistical power. Expert agreement has been voted. A panel of experts defined neuropsychological consensus procedure for French patients according to psychometric determinants of cognitive tests, specificity of epilepsy, surgery context, French culture, and literature reports. More specifically, objectives and framework for NAP and test selection were defined. Experts voted for each cognitive domain assessment based on their clinical experience and the strength of supporting evidence. Each task or procedure was defined with more than $90 \%$ of approval.

\subsection{Neuropsychological consensus procedure based on the opinion of the expert panel}

\subsubsection{Objectives of NAP}

There are numerous reasons for conducting a neuropsychological assessment for patients with epilepsy including documenting the cognitive profile, learning about the patient's strengths and weaknesses, assessing cognitive behavior related to antiepileptic treatment, measuring cognitive changes over time, and suggesting adequate cognitive and behavioral counseling and therapy $[7,11,12]$.

In the case of surgery as a treatment for drug-resistant epilepsy, a neuropsychological evaluation is crucial to:

1) describe the neuropsychological profile and establish baseline before surgery;

2) contribute to lateralizing and localizing cognitive dysfunction in relation to the epileptic syndrome (e.g., focus, seizure frequency, antiepileptic drugs (AEDs), age at onset, disease duration);

3 ) estimate cognitive outcome relative to functional adequacy model and mental reserve capacities [5,6]: determine risks and benefits in regard to surgery;

4) take into consideration psychological status in the final surgery decision;

5) estimate the need for neuropsychological rehabilitation and/or psychosocial and/or behavioral therapies pre- and postoperatively;

6) assess cognitive outcome following surgery. 


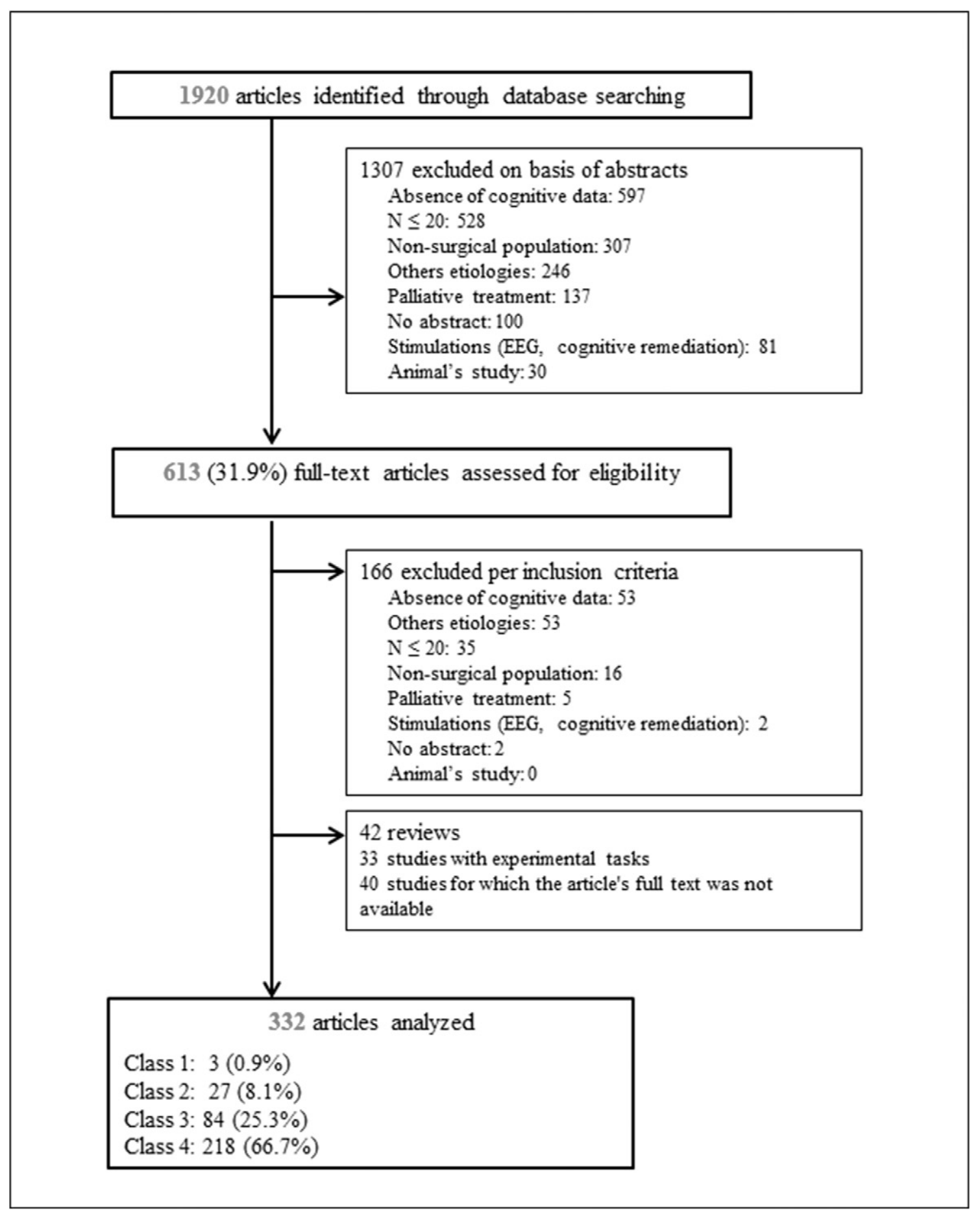

Fig. 1. Flowchart of the study.

\subsubsection{Neuropsychological assessment procedure}

This consensus follows ethical and clinical considerations [13]. French neuropsychological procedure includes:

1) an exhaustive report on demographical, socioeducational variables, personal and cultural background, patient's complaints and expectations, handedness, epileptic variables (age at onset, focus, seizure frequency, disease duration) and comorbidities, medication, fatigue and sleep, psychoactive substance use, past or ongoing assessments, treatments and therapies;

2) a psychological and behavioral interview and questionnaires (see Table 1);
3) a comprehensive neuropsychological testing using required and optional tools (see Table 1 );

4) a restitution of test results.

In France, assessment must be conducted by a clinical neuropsychologist. In the surgical context, NAP should be performed in optimal conditions: usual AEDs, far from last seizure, without sleep deprivation, in a quiet office. The minimal estimated duration required to complete the tests is approximately $5 \mathrm{~h}$, distributed into two sessions with breaks. It is important to take into consideration additional time ( $3 \mathrm{~h}$ ) for interpretation, restitution to the patient and medical team, and report redaction. Preoperative NAP should be performed within the year preceding 
Table 1

French neuropsychological procedure consensus.

\begin{tabular}{|c|c|c|}
\hline $\begin{array}{l}\text { COGNITIVE } \\
\text { DIMENSIONS }\end{array}$ & REQUIRED TESTS & OPTIONAL TESTS \\
\hline & \multicolumn{2}{|l|}{ ANAMNESIS } \\
\hline \multicolumn{3}{|c|}{ INTELLECTUAL EFFICIENCY } \\
\hline Intellectual efficiency & $\begin{array}{l}\text { Wechsler Adult Intelligence Test-Fourth edition } \\
\text { (WAIS-IV) } \\
\text { Parallel form : no }\end{array}$ & - \\
\hline \multicolumn{3}{|c|}{ LONG TERM MEMORY } \\
\hline Verbal memory & $\begin{array}{l}\text { High socio-educational level } \\
\text { Selective Reminding Test }{ }^{2} \\
\text { Parallel form : yes (2) } \\
\text { Low socio-educational level } \\
\text { 16-item Free and Cued Recall }{ }^{3} \\
\text { Parallel form : yes (3) } \\
\text { AND } \\
\text { Auditory Memory Index } \\
\text { Wechsler Memory Scale - Fourth Edition (WMS- } \\
\text { IV) }{ }^{4} \\
\text { Parallel form : no }\end{array}$ & - \\
\hline Non-verbal memory & $\begin{array}{c}\text { Brief Visuospatial Memory Test - Revised } \\
\text { (BVMT-R })^{5} \\
\text { Parallel form : yes (6) } \\
\text { and /or } \\
\text { The Rey-Osterrieth complex figure test } \\
\text { (ROCF })^{6} \\
\text { Parallel form : yes (2) } \\
\text { And } \\
\text { Faces Recognition } \\
\text { Wechsler Memory Scale - } \\
\text { Third Edition (WMS-III) } \\
\text { Parallel form : no }\end{array}$ & - \\
\hline $\begin{array}{l}\text { Autobiographical } \\
\text { memory }\end{array}$ & - & TEMPau $^{8}$ \\
\hline \multicolumn{3}{|c|}{ SHORT TERM \& WORKING MEMORY } \\
\hline Short term memory & $\begin{array}{c}\text { Digit span forward (WAIS-IV) } \\
\text { Parallel form : no } \\
\text { Corsi block-tapping test forward } \\
\text { Parallel form : no }\end{array}$ & - \\
\hline Working memory & $\begin{array}{l}\begin{array}{l}\text { Digit span backward (WAIS-IV) } \\
\text { Parallel form : no }\end{array} \\
\text { Corsi block-tapping test backward } \\
\text { Parallel form : no }\end{array}$ & $\begin{array}{c}\text { Working memory (Test of Attentional } \\
\text { Performance) } \\
\text { Parallel form : no } \\
\text { Paced Auditory Serial Addition Test (PASAT) } \\
\text { Parallel form : no }\end{array}$ \\
\hline \multicolumn{3}{|l|}{ ATTENTION } \\
\hline Alertness & - & $\begin{array}{l}\text { Reaction times (Test of Attentional Performance) })^{9} \\
\text { Parallel form : no }\end{array}$ \\
\hline Selective attention & $\begin{array}{c}\mathrm{D} 2-\mathrm{R}^{19} \\
\text { Parallel form : no }\end{array}$ & - \\
\hline Divided attention & $\begin{array}{c}\text { Divided attention (Test of Attentional } \\
\text { Performance) } \\
\text { Parallel form: no }\end{array}$ & - \\
\hline Sustained attention & $\begin{array}{c}\text { Sustained attention (Test of Attentional } \\
\text { Performance) }{ }^{9} \\
\text { Parallel form }: \text { no }\end{array}$ & - \\
\hline \multicolumn{3}{|c|}{ EXECUTIVE FUNCTIONS } \\
\hline Shifting & $\begin{array}{l}\text { Trail Making Test } \mathrm{B}^{11} \\
\text { Parallel form : no }\end{array}$ & $\begin{array}{l}\text { Flexibility (Test of Attentional Performance) }{ }^{9} \\
\text { Parallel form : no }\end{array}$ \\
\hline
\end{tabular}




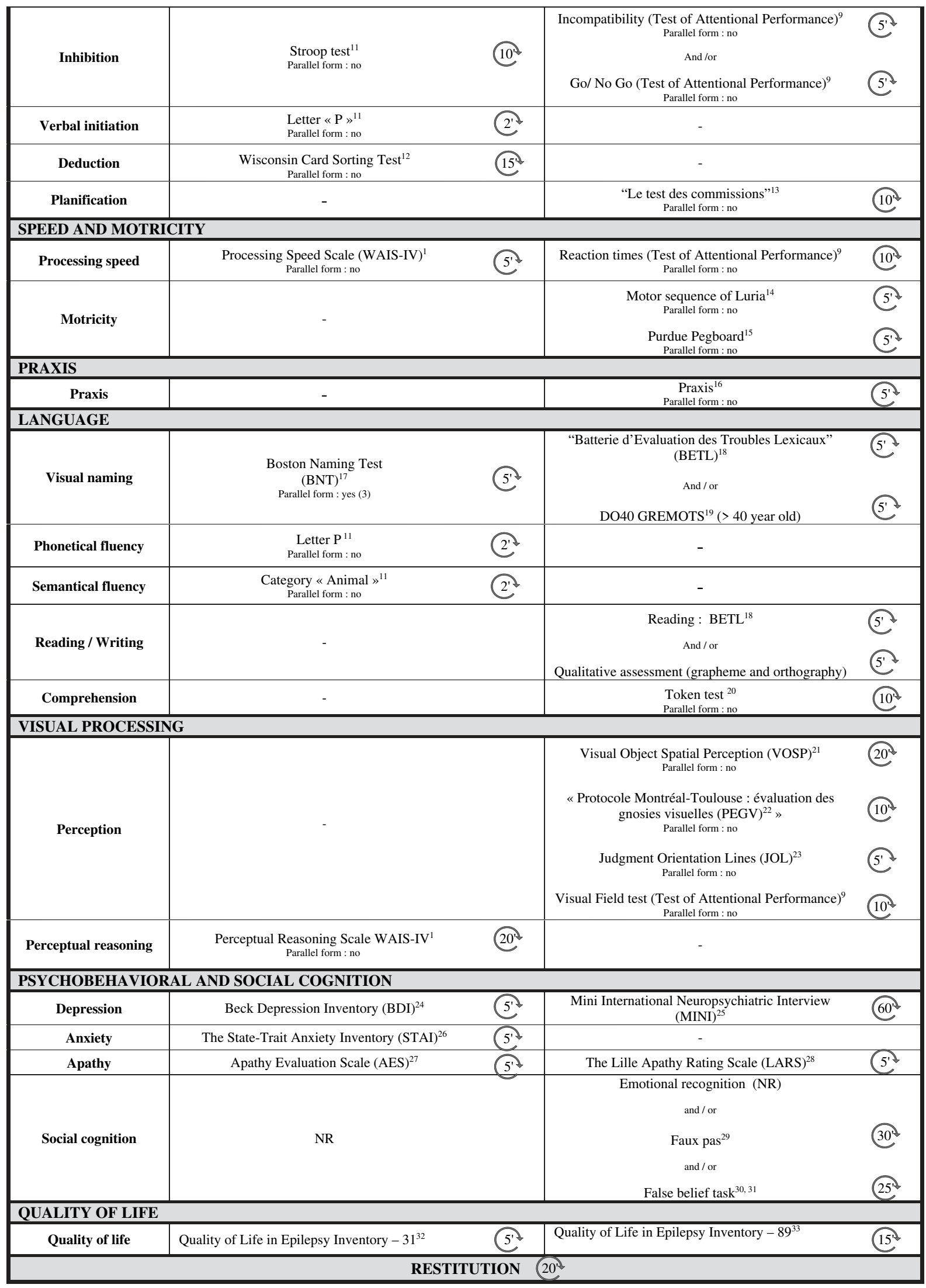

Tests references ( 1 to 33 ) are provided in Appendix D in Supplementary data.

${ }^{1}$ Wechsler, 2012 - ${ }^{2}$ Dujardin et al., 2004 - ${ }^{3}$ Van der Linder et al. $2004-{ }^{4}$ Wechsler, $2012-{ }^{5}$ Benedict et al., $1996-{ }^{6}$ Wallon et al., $2009-{ }^{7}$ Wechsler, $2001-{ }^{8}$ Piolino et al., 2000 - ${ }^{9}$ Zimmermann \& Fimm, $1995-{ }^{10}$ Brickenkamp et al., 2010 - ${ }^{11}$ Roussel \& Godefroy, $2008-{ }^{12}$ Heaton et al., 2007 - ${ }^{13}$ Martin, $1972-{ }^{14}$ Luria, $2012-{ }^{15}$ Tiffin, $2010-$

${ }^{16}$ Mahieux-Laurent et al., $2009-{ }^{17}$ Colombo \& Assal, 1992 // Roussel \& Godefroy, $2016-{ }^{18}$ Tran \& Godefroy, $2011-{ }^{19}$ Bézy et al., 2016 - ${ }^{20}$ De Renzi \& Faglioni, 1978 -

${ }^{21}$ Warrington \& James, $1991-{ }^{22}$ Agniel et al., $1993-{ }^{23}$ Benton et al., $1983-{ }^{24}$ Beck, $1998-{ }^{25}$ Lecrubier et al., $1998-{ }^{26}$ Gauthier \& Bouchard, $1993-{ }^{27}$ Marin et al., $1991-$

${ }^{28}$ Sockeel et al., 2006 - ${ }^{29}$ Delbeuck et al., 2010 - ${ }^{30}$ Desgranges et al., 2012- ${ }^{31}$ Biervoye et al., 2018 - ${ }^{32}$ Picot et al., 2004 - ${ }^{33}$ Cramer et al., 1998 - NR: no recommendation. 
surgery. Postoperative NAP should be performed between six and twelve months following surgery, and repeated at two and five years after [14]. A systematic exploration of several cognitive domains, according to ILAE [7], is recommended: intellectual efficiency, long-term memory, short-term and working memory, attention, executive functions, processing speed and motor skills, language, visual processing, praxis, psychobehavior, and social cognition.

Table 1 summarizes required and optional neuropsychological tests for French patients. Approximate duration of required test is $8 \mathrm{~h}$, including anamnesis and restitution.

\section{Discussion}

A French Chapter of the ILAE of experts in the neuropsychology of epilepsy discuss and define a common procedure for assessing cognitive and psychobehavioral function in surgical French patients in regard to systematic literature review.

Low scientific evidence of neuropsychological data was reported in this literature review. Indeed, in epilepsy surgery, a lack of randomized control trials and prospective studies with large samples of participants is reported, especially regarding neuropsychological assessment [8]. Furthermore, there is a high variability in neuropsychological tools, and few of them were not validated in French language with robust psychometric qualities, parallel forms, recent, and appropriate normative data.

In epilepsy surgery, NAP is part of a multidisciplinary approach in connection with other examinations such as clinical semiology, magnetic resonance imaging (MRI), functional MRI, positron-emission tomography (PET)-scan, and EEG recordings. Neuropsychological profile contributes to the location of the epileptogenic focus in focal epilepsy, as cognitive and/or behavioral impairment can provide evidence of lateralization and location of the epileptogenic network.

With consensus, a panel of experts recommends a systematic exploration of the following dimensions, as reported by ILAE [7]: intellectual efficiency, long-term memory, short-term and working memory, attention, executive functions, processing speed and motor skills, language, visual processing, praxis, psychobehavior, and social cognition. Test selection has been established according to psychometric determinants, specificity of epilepsy, surgical context, French culture, and literature reports.

Concerning intellectual efficiency, a consensus was obtained for the use of Wechsler Adult Intelligence Scale fourth edition [9] in the epileptic population. This scale is used to detect specific developmental learning deficits, and/or disharmony in competencies. Four indices can be computed: the verbal comprehension index (VCI), the perceptual reasoning index (PRI), the processing speed index (PSI), and the working memory index (WMI). The full-scale intelligence quotient (FSIQ) is calculated only if indices are homogenous. Full-scale intelligence quotient may significantly underestimate levels of general intellectual ability in people with epilepsy. Inaccurate representations of FSIQ due to selective impairment in working memory and reduced processing speed obscure the contextual interpretation of performance on other neuropsychological tests, and subtle localizing and lateralizing signs may be missed as a result. With this fourth edition, a general ability index (GAI) that lowers the impact of processing speed and working memory, can be calculated. Moreover, GAI-FSIQ discrepancies are correlated with the number of AEDs, age at onset, and duration of epilepsy [15]. In NAP, the GAI-FSIQ provides an intellectual profile and a frame for the choice and interpretation of all cognitive tests.

Memory impairment is frequently reported before and after epilepsy surgery in particular in temporal lobectomy $[4,16,17]$. Episodic memory must therefore be explored using a rigorous examination. We recommend testing both verbal and nonverbal modalities. Using more than one task in each modality will provide information on encoding, learning, remembering, and forgetting processes as well as memorization of structured, unstructured, associative, abstract, or concrete material. Suggested French tools include immediate and delayed recalls, however, maximum delay available is $35 \mathrm{~min}$. In this context, accelerated forgetting (delay more than $4 \mathrm{~h}$ ) frequently observed in temporal lobe epilepsy $[18,19]$ cannot be explored. Currently, many research studies focus on this important phenomenon [20,21], and French normative data is expected in the future with $4 \mathrm{~h}, 24 \mathrm{~h}$, and a one-week delays.

Concerning short-term and working memory, spans are widely recognized as a useful assessment task in verbal and nonverbal modalities. Regarding working memory, required tests explore mental load, and optional tests are provided to assess updating.

Assessing attentional processes in epilepsy is required by ILAE [7]. Attention is divided into several dimensions: alertness, selective attention, divided attention and sustained attention [22]. Some AEDs may have a direct positive effect on cognitive performance by improving alertness and cognitive abilities in epilepsy [23]. Negative effects of AEDs on attention could depend on used posology and could therefore be improved by pre and posttreatment introduction. Improvement of attention was described after surgery [23] and interpreted as the result of a general cognitive improvement [24]. Therefore, we recommend assessing three attentional processes among those described.

Impairment in executive functions is observed in epilepsy regardless of the location of epileptogenic zone $[25,26]$ and postoperative improvement can be reported [4]. Executive functions as defined by GREFEX group (French executive functions task force providing French normative data) [27] include shifting, inhibition, verbal initiation, deduction, planning, and memory retrieval. A large assessment is therefore recommended with at least three functions.

Language is characterized by a complex brain network, depending mainly on dominant hemisphere functions, which can vary significantly between individuals. In epilepsy, there is a higher percentage of atypical language representations [28]. Furthermore, language functions can be affected by epilepsy, and their assessment is crucial before surgery [29]. Language has a localizing, lateralizing, and even physiopathological value, to maximize surgical success [30,31]. The most frequently observed deficit is naming deficit [32]. Language disorders are more frequently observed in left temporal lobe epilepsy (TLE), but a significant proportion of patients with right TLE shows deficits too [32]. Language assessment should include receptive and productive verbal tasks, as well as oral and written modalities. A comprehensive language assessment by a speech-therapist is also useful for documentation. As appropriate, functional MRI with specific language paradigms could be added.

Concerning visual processing, a perceptual reasoning index is assessed in WAIS-IV. Optional visuoperceptual and visuospatial tests (visual field, orientation judgment, gnosis, face processing) may be added, especially in posterior epilepsy [33].

Finally, NAP must include psychobehavioral dimension, because increased rates of psychiatric disturbances are observed in patients with epilepsy, with respect to the general population [34]. In surgery, a specific assessment is necessary to interpret the overall clinical profile. Depression, apathy, anxiety, and quality of life should be explored using scales and interviews with a psychiatrist and/or psychologist. A high prevalence of depression [34] or more generally emotional dysregulation [35] has been reported, which can interfere with postoperative outcome. Confounding factors, such as sleep disturbances, fatigue, AEDs effects, need to be considered. Similarly, the impact of social cognition impairment on the psychosocial functioning and quality of life of patients is often suspected but remains to be clarified. Some research studies point to the presence of social cognition disorders in patients with epilepsy [36-38]. In clinical practice, social cognition abilities remain insufficiently explored in patients with epilepsy, and no consensual assessment of social cognition skills is defined. Further investigations appear necessary to determine the characteristics, the prevalence, as well as the impact of epilepsy surgery. In this context, an assessment of social cognition abilities is encouraged, including emotional processing and theory of mind.

Neuropsychological assessment is essential and systematically required in epilepsy surgery $[39,40]$. The main goal of NAP is to estimate 
cognitive outcome relative to the functional adequacy model and mental reserve capacities, and to determine risks and benefits in regard to surgery. With this in mind, the first French neuropsychological procedure consensus has been established and includes a comprehensive procedure with structured longitudinal steps. Pre- and postoperative assessments are systematically required to anticipate neuropsychological outcome following surgery. Preoperative evaluation delay is within one year before surgery, and postoperative is from 6 months to 1 year, 2 years and 5 years of follow-up, because several longitudinal studies show cognitive improvement in the long term, depending on seizure's control $[14,41]$. NAP requires trained professionals, appropriate and recent psychometric tools, and time constraints ( 6 to $8 \mathrm{~h}$ for each NAP) in order to fully document the overall profile and improve patient care in epilepsy units.

These French neuropsychological procedures reflect a current consensus, in relation to the availability of French tests, and they may of course be perfectible in the future. The psychometric qualities (sensitivity and specificity) of these tests are not all perfect, and some tests have not been validated for patients with epilepsy especially, that's why neuropsychological researches should therefore be encouraged and financially supported to develop appropriate tests for patients with epilepsy, specific to each country, in particular regarding long-term memory and social cognition. This work highlights a significant willing to improve neuropsychological evaluation of French patients with epilepsy who are candidates to surgery.

\section{Conclusion}

A common procedure for assessing cognitive and psychobehavioral function for patients with epilepsy undergoing surgical evaluation is now available and has been established, which may help to improve the quality of care and the patient experience. This work highlights the need of further investigations and the necessity to develop specific tools with normative data.

\section{Ethical publication statement}

We confirm that we have read the journal's position on issues involved in ethical publication and affirm that this report is consistent with those guidelines.

\section{Acknowledgments}

The authors would like to thank French League Against Epilepsy Ligue Française Contre l'Epilepsie (LFCE) for its financial support which allowed the establishment of the Neuropsychology Task force.

\section{Declaration of competing interest}

NF reports personal fees from UCB Pharma. The remaining authors have no financial disclosures to make.

\section{Appendix A. Supplementary data}

Supplementary data (Appendix A to D) to this article can be found online at https://doi.org/10.1016/j.yebeh.2019.106522.

\section{References}

[1] Fisher RS, Boas WVE, Blume W, Elger C, Genton P, Lee P, et al. Epileptic seizures and epilepsy: definitions proposed by the International League Against Epilepsy (ILAE) and the International Bureau for Epilepsy (IBE). Epilepsia. 2005:470-2. https://doi. org/10.1111/j.0013-9580.2005.66104.x.

[2] Witt JA, Helmstaedter C. Should cognition be screened in new-onset epilepsies? A study in 247 untreated patients. J Neurol. 2012;259(8):1727-31. https://doi.org/ 10.1007/s00415-012-6526-2.

[3] Engel J. The current place of epilepsy surgery. Curr Opin Neurol. 2018;31(2):192-7.

[4] Sherman E, Wiebe S, Fay-McClymont T, Tellez-Zenteno J, Metcalfe A, HernandezRonquillo L, et al. Neuropsychological outcomes after epilepsy surgery: systematic review and pooled estimates. Epilepsia. 2011;52:857-69. https://doi.org/10.1111/j. 1528-1167.2011.03022.x.

[5] Chelune G. Hippocampal adequacy versus functional reserve: predicting memory functions following temporal lobectomy. Arch Clin Neuropsychol. 1995;10:413-32. https://doi.org/10.1016/0887-6177(95)00015-V.

[6] Helmstaedter C. Prediction of memory reserve capacity. Adv Neurol. 1999;81:271-9. 10609023.

[7] Wilson S, Baxendale S, Barr W, Hamed S, Langfitt J, Samson S, et al. Indications and expectations for neuropsychological assessment in routine epilepsy care: report of the ILAE Neuropsychology Task Force, Diagnostic Methods Commission, 20132017; 2019. https://doi.org/10.1111/epi.13055.

[8] Vogt VL, Äikiä M, Barrio A, Boon P, Borbély C, Bran E, et al. Current standards of neuropsychological assessment in epilepsy surgery centers across Europe. Epilepsia. 2017;58(3):343-55. https://doi.org/10.1111/epi.13646.

[9] Wechsler D. Wechsler Adult Intelligence Scale-IV (WAIS-IV). New York: Psychological Corporation; 2011.

[10] Rosenow F, Bast T, Czech T, Feucht M, Hans VH, Helmstaedter C, et al. Revised version of quality guidelines for presurgical epilepsy evaluation and surgical epilepsy therapy issued by the Austrian, German, and Swiss working group on presurgical epilepsy diagnosis and operative epilepsy treatment. Epilepsia. 2016;57(8): $1215-20$.

[11] Samson S. L'évaluation neuropsychologique dans la chirurgie de l'épilepsie. In: Seron $\mathrm{X}$, Van der Linden M, editors. Traité de neuropsychologie clinique de l'adulte: Tome 1- Evaluation. De Boeck Superieur; 2014. p. 619-35.

[12] Brissart $H$, Volfart A. Evolution des fonctions cognitives après chirurgie du lobe temporal. In: Brissart H, Maillard L, editors. Neuropsychologie des épilepsies de l'adulte: Approche clinique et pratique. De Boeck Supérieur; 2018. p. 96-108.

[13] Thomas-Antérion C, Barbeau E. Neuropsychologie en pratique (s). , vol. 20Marseille: Solal; 2011.

[14] Helmstaedter C, Elger C, Vogt V. Cognitive outcomes more than 5 years after temporal lobe epilepsy surgery: remarkable functional recovery when seizures are controlled; 2019. https://doi.org/10.1016/j.seizure.2018.09.023.

[15] Baxendale S, McGrath K, Thompson PJ. Epilepsy \& IQ: the clinical utility of the Wechsler Adult Intelligence Scale-Fourth Edition (WAIS-IV) indices in the neuropsychological assessment of people with epilepsy. J Clin Exp Neuropsychol. 2014; 36(2):137-43. https://doi.org/10.1080/13803395.2013.870535.

[16] Helmstaedter C, Schramm J, Elger CE. 15 years epilepsy surgery in Bonn: cognitive and seizure outcome. Epilepsia. 2007;48:14.

[17] Helmstaedter C. Neuropsychological outcomes of different surgical approaches in temporal lobe epilepsy. In: Helmstaedter C, Hermann B, Lasonde M, et al, editors. Neuropsychology in the care of people with epilepsy. Progress in epileptic disorders. Montrouge: John Libbey; 2011. p. 201-21.

[18] Blake RV, Wroe SJ, Breen EK, McCarthy RA. Accelerated forgetting in patients with epilepsy: evidence for an impairment in memory consolidation. Brain. 2000;123 (Pt 3):472-83.

[19] Tramoni E, Felician O, Barbeau EJ, Guedj E, Guye M, Bartolomei F, et al. Long-term consolidation of declarative memory: insight from temporal lobe epilepsy. Brain. 2011;134(3):816-31. https://doi.org/10.1093/brain/awr002.

[20] Manoli R, Chartaux-Danjou L, Mecheri H, Delecroix H, Noulhiane M, Moroni C. Extension to one week of verbal memory consolidation assessment. Neuropsychology. 2018;32(3):366-73. https://doi.org/10.1037/neu0000403.

[21] Lemesle B, Planton M, Pagès B, Pariente J. Accelerated long-term forgetting and au452 tobiographical memory disorders in temporal lobe epilepsy: one entity or two? Rev Neurol. 2017;173(7-8):498-505.

[22] Cohen RA. The neuropsychology of attention. 2nd ed.. New York: Springer; 2014.

[23] Helmstaedter C, Richter S, Röske S, Oltmanns F, Schramm J, Lehmann TN. Differential effects of temporal pole resection with amygdalohippocampectomy versus selective amygdalohippocampectomy on material-specific memory in patients with mesial temporal lobe epilepsy. Epilepsia. 2008;49(1):88-97. https://doi.org/10.1111/j. 1528-1167.2007.01386

[24] Helmstaedter C, Kurthen M, Lux S, Reuber M, Elger CE. Chronic epilepsy and cognition: a longitudinal study in temporal lobe epilepsy. Ann Neurol. 2003;54(4): 425-32. https://doi.org/10.1002/ana.10692.

[25] Helmstaedter C, Gleissner U, Zentner J, Elger CE. Neuropsychological consequences of epilepsy surgery in frontal lobe epilepsy. Neuropsychologia. 1998;36(7):681-9 [PMID: 9723939. 21].

[26] Witt JA, Elger CE, Helmstaedter C. Adverse cognitive effects of antiepileptic pharmacotherapy: each additional drug matters. Eur Neuropsychopharmacol. 2015;25: 1954-9. https://doi.org/10.1016/j.euroneuro.2015.07.027.

[27] Roussel M, Godefroy O. La batterie GREFEX: données normatives. In: Godefroy et le GREFEX, editor. Fonctions exécutives et pathologies neurologiques et psychiatriques. Marseille: Solal Eds; 2008. p. 231-52.

[28] Möddel G, Lineweaver T, Schuele SU, Reinholz J, Loddenkemper T. Atypical language lateralization in epilepsy patients. Epilepsia. 2009;50(6):1505-16. https://doi.org/ 10.1111/j.1528-1167.2008.02000.x.

[29] Hermann B. The effects of localization-related epilepsy on language lateralization and networks. Epilepsy Currents. 2006;6(4):114-6. https://doi.org/10.1111/j.15357511.2006.00115.

[30] Drane DL, Ojemann JG, Kim MS, Gross RE, Miller JW, Faught JrRE, et al. Interictal epileptiform discharge effects on neuropsychological assessment and epilepsy surgical planning. Epilepsy Behav. 2016;56:131-8. https://doi.org/10.1016/j.yebeh.2016.01.001.

[31] Drane DL, Pedersen NP. Knowledge of language function and underlying neural networks gained from focal seizures and epilepsy surgery. Brain Lang. 2019;189:20-33. https://doi.org/10.1016/j.bandl.2018.12.007.

[32] Bartha-Doering L, Trinka E. The interictal language profile in adult epilepsy. Epilepsia. 2014;55(10):1512-25. https://doi.org/10.1111/epi.12743. 
[33] Drane DL, Ojemann JG, Phatak V, Loring DW, Gross RE, Hebb AO, et al. Famous face identification in temporal lobe epilepsy: support for a multimodal integration model of semantic memory. Cortex. 2013;49(6):1648-67. https://doi.org/10.1016/j.cortex. 2012.08.009.

[34] Josephson CB, Jetté N. Psychiatric comorbidities in epilepsy. Int Rev Psychiatry. 2017; 29(5):409-24. https://doi.org/10.1080/09540261.2017.1302412.

[35] Blumer D, Montouris G, Davies K. The interictal dysphoric disorder: recognition, pathogenesis, and treatment of the major psychiatric disorder of epilepsy. Epilepsy Behav. 2004;5(6):826-40. https://doi.org/10.1111/j.1528-1167.2009.02424.x.

[36] Bora E, Meletti S. Social cognition in temporal lobe epilepsy: a systematic review and meta-analysis. Epilepsy Behav. 2016;60:50-7. https://doi.org/10.1016/j.yebeh.2016. 04.024.

[37] Edwards M, Stewart E, Palermo R, Lah S. Facial emotion perception in patients with epilepsy: a systematic review with meta-analysis. Neurosci Biobehav Rev. 2017;83: 212-25. https://doi.org/10.1016/j.neubiorev.2017.10.013 22
38] Giovagnoli AR, Parente A, Didato G, Deleo F, et Villani F. Expanding the spectrum of cognitive outcomes after temporal lobe epilepsy surgery: a prospective study of theory of mind. Epilepsia. 2016;57(6):920-30. https://doi.org/10.1111/epi.13384.

[39] Baxendale S. Neuropsychological assessment in epilepsy. Pract Neurol. 2018;18(1): 43-8. https://doi.org/10.1136/practneurol-2017-001827.

[40] Jones-Gotman M, Smith ML, Risse GL, Westerveld M, Swanson SJ, Giovagnoli AR, et al. The contribution of neuropsychology to diagnostic assessment in epilepsy. Epilepsy Behav. 2010;18(1-2):3-12. https://doi.org/10.1016/j.yebeh.2010.02.019.

[41] Giovagnoli AR, Parente A, Didato G, Manfredi V, Deleo F, Tringali G, et al. The course of language functions after temporal lobe epilepsy surgery: a prospective study. Eur J Neurol. 2016;23(12):1713-21. https://doi.org/10.1111/ene.13113. 